Behavioural Neurology, 1988, 1, 11-22

\title{
Persistent Left Unilateral Apraxia and a Disconnection Theory
}

\author{
ATSUSHI YAMADORI, ${ }^{1}$ YUKIO OSUMI,${ }^{1}$ TORU IMAMURA ${ }^{1}$ and \\ YOKO MITANI ${ }^{2}$ \\ ${ }^{1}$ Neurology Service, Hyogo Brain and Heart Center at Himeji 520 Saisho-Ko, Himeji, Hyogo-ken, \\ 670, Japan \\ ${ }^{2}$ Neuropsychology Section, Hyogo Brain and Heart Center at Himeji, Japan
}

\begin{abstract}
A case of persistent left unilateral apraxia caused by a post-traumatic callosal lesion is reported. Based on an analysis of the nature of the motor disturbances it is concluded that the disconnection is neither for linguistic nor mnemonic information about praxis but motor control information which is activated through conscious intention.
\end{abstract}

\section{Introduction}

One of the intriguing problems in left unilateral apraxia secondary to callosal damage is actually what kind of neural information is refused to the right hemisphere. Representative answers so far proposed include information about skilled motor movements, i.e. die kinetischen Engramme (Liepmann, 1908 ; 1920) or visuo-kinesthetic motor engrams (Watson, 1983), linguistic information about motion (Geschwind, 1962; Volpe, 1982), or capacity to associate verbal comprehension and motor channeling (Zaidel, 1977). All these theories depend on firm observations and apply well to the particular data presented. Recently we have encountered a long standing case of callosal disconnetion syndrome manifesting all symptoms of motor-tactovisuo-audio-verbal disconnetion. We have been particularly interested in the nature of his left unilateral motor disturbance and concluded that none of the above-mentioned theories is satisfactory in explaining our patient's apraxia.

An important aspect of apraxia includes a well-known principle of automatico-voluntary dissociation originally formulated by Jackson and Baillarger (Alajouanine, 1960). The principle states that a motor performance failed in a testing situation can be observed to be easily done in a more natural situation. Thus in apraxia voluntary control of the motor apparatus is affected while automatic control is preserved.

\section{Case Report}

T.S., a 21-year-old right-handed college student, while driving, collided with another car on $1 \mathrm{March}, 1985$. He was immediately brought into a nearby hospital in a comatose state. On admission his pupils were miotic $0953-4180 / 88 / 010011+12 \$ 3.50 / 0 \quad$ (C) 1988 CNS (Clinical Neuroscience) Publishers 
without reaction to light. Weak right-sided movements were noted on strong pinching. CT scan of the brain revealed haemorrhage in the right medial frontal lobe, and blood filled and enlarged the lateral ventricles. Ventricular drainage was attempted. Coma persisted with bilateral decerebrate posturing, ocular bobbing, pinpoint pupils and absent doll's eye signs. Gradually he started to improve. In April a V-P shunt was inserted to reduce hydrocephalus. Slow recovery continued and by the end of May spontaneous movements of limbs and spontaneous verbal output appeared. By the end of August he was walking with support. In October he started to walk without a cane but left-sided paresis was said to be apparent. In September next year, 19 months after the accident, a psychiatric consultant recorded his mental state as characterized by Korsakoff's syndrome, Witzelsucht, euphoria and personality change. Because the parents thought that their son was still improving he was referred to our Neurology Service for further evaluation on 14 October, 1986, 20 months after the accident.

\section{Neurological Status on Admission}

Visual field on confrontation was full. Pupils were $4 \mathrm{~mm}$ and equal, but reacted to light sluggishly. Convergence of the eyes was absent. Other cranial nerves were intact. Gait was awkward with wide base and small step but he could walk alone. Standing up from the sitting position was often difficult without help. Motor tone of four limbs was judged to be normal. At first the left hand was thought to be slightly weak, but it was noted to have normal power when encouraged to exert stronger power. Individual fingers all had normal power bilaterally. Deep tendon reflexes were normal and no pathological reflexes were elicited. No grasp response was present. Coordination was normal including visually guided reaching. Sensory system was normal for pain, temperature, position, touch and vibration.

\section{Neuropsychological Status through the Hospital Stay}

The patient was euphoric and jocular. Attention was easily distracted by irrelevant stimuli. Orientation for time was correct but orientation for place was incorrect being unable to remember the name of the hospital to which he was newly admitted. Memory was impaired: digit span was 5 forward at his best, recent memory for 3 names was 0 in $5 \mathrm{~min}$ but increased to 2 if places that had been hidden were to be answered. Remote memory was fair up to the time he was admitted to the college. No aphasia was observed. Agnosia for objects was not found. No unilateral neglect was present. Buccofacial apraxia was not seen. Intelligence score by WAIS was low: verbal 79, and performance below 60 . Beside these findings, the patient showed selective motor and tactile impairment which was strictly lateralized to the left hand. The right hand was completely free from the symptoms mentioned below. 


\section{Motor Aspects of the Left Hand}

Observations of his natural behaviour. The left hand showed good movements under freely behaving conditions. He would hold a cup with the left hand adroitly. He could pick up a small pin or ball with the left hand without trouble. He would put on clothes without difficulty. Thus his mother found no problems with his left hand although it had been weak initially.

Initiation of action on verbal command. When asked to hold a cup with the left hand, he occasionally found it difficult to start the action promptly. $\mathrm{He}$ would remain immobile for a while, or he would start the movement by verbally facilitating the demanded action. Even when he was asked to raise his hands as in Barre's test, only the right hand would be raised. It took some time for him to start raising the left arm. It should be noted that these difficulties of initiation were not a constant finding. Nevertheless they could be observed throughout his hospital stay.

Conventional sign gesture. On verbal command his gesturing for waving good-bye, beckoning or saluting was amorphic and incomplete. But intention of the action was discernible. These actions did not improve with visual imitation.

Pantomiming the use of objects. In drinking a cup of tea, the position of the wrist was inappropriate. Also, the mouth opened before the left hand was at the mouth. In brushing the teeth, movements of the left hand were amorphic and imprecise. In hammering, not an imagined hammer but the whole forearm itself was moved. Thus those movements seemed fair at a glance but essentially unsatisfactory if closely inspected. Imitation did not improve the performance.

Object manipulation. A cup was brought to the mouth fairly smoothly. But the mouth opened for drinking before the cup was at the mouth, and when the cup was there the mouth would not open. Tooth brushing was fair but imprecise. Hammering was also imprecise the hammer was moved not only up and down but also antero-posteriorly. In using scissors the blades could be opened and closed, but because the scissors could not be stabilized at a fixed position, they would not cut a sheet of paper.

Elementary movements of the left fingers. Ability to use a single finger on verbal command was faulty. For instance he would move the little finger for the index finger. Initiation also was often difficult. On visual imitation the situation did not improve. However, when the examiner touched a finger and told him to move the touched one, the response became completely normal for all the fingers, demonstrating it was not motor clumsiness of the pyramidal or extrapyramidal type that was concerned. But when a finger of the right hand was touched and the corresponding contralateral finger was to be moved, incorrectness of the innervation of the left fingers reappeared. 
Innervatory ability for finger pattern was also defective. But there were occasions when he could produce them correctly. For instance, he produced a pattern of "fox head" (extension of the second and the fifth finger and closing of the third and the fourth finger with the thumb) promptly and correctly on verbal command. But when asked to make a sign of money (closing of the index finger with the thumb and extension of the rest), he promptly produced the previous fox-head. Imitation was also incorrect and again perseveration was often observed. When the examiner imposed a pattern on his fingers, he could always reproduce the pattern smoothly.

Sequential movement of the left upper arm. Luria's palm-edge-fist test (Luria, 1966) was impossible for the left arm. The same movement would often be repeated, the patient being unable to change to the next pattern. Luria's test of tapping the table with the first, third, and fifth finger successively (piano play) was also difficult. Even the simple rhythm reproduction of triple time could not be done. He could not maintain a regular speed or the hand started to scratch the table. But if this rhythm was produced by clapping the hands, the left hand followed the right quite correctly.

Writing with the left hand. His way of holding a pencil was correct, but he would often remain immobile with that posture. Prompting did not help. $\mathrm{He}$ would complain he could not write. Occasionally he did produce his family name with Kanji correctly. Once he perseverated Kanji letter of "tree" several times.

Drawing and construction with the left hand. He could not copy a circle or triangle. He could only copy horizontal or vertical lines. With Koh's cubes even a simple pattern composed of 4 cubes was difficult.

Coordination of both hands. Clapping of hands was smooth. Tying and untying a string was done quite well employing both hands.

\section{Sensory Aspects of the Left Hand}

As described already sensory status for touch, pain, temperature, position and vibration was normal. However he showed impairments in discriminative perception in the left hand. Point localization was incorrect by verbal response as well as by ipsilateral thumb pointing.

Two point discrimination was $0.3 \mathrm{~cm}$ at the tip of the right index finger and about $8 \mathrm{~cm}$ on the palm side of the left index finger. Directional cutaneous kinesthesia (Bender, 1982) was all correct bilaterally. Graphesthesia for numbers on the left palm in three separate tests were $6 / 10,2 / 5,4 / 6$ correct respectively. No error was seen on the right.

For stereognosis, verbal description of a form board of about $8 \mathrm{~cm}$ in diameter held in the left hand was incorrect. However, the left hand could pick up the same one from three dissimilar boards, i.e. circle, cross and triangle, without vision, but the task was performed extremely slowly. The 
left hand did not explore the contour of these objects actively and would often remain immobile with an object in the hand. Frequent encouragement was necessary to have him continue the task. He could also fit these forms into the corresponding mould correctly, but, again it was extremely slow. The left hand would stay where it was and the patient complained that he had no idea how and where he should bring it. It was often necessary to guide his left hand to an appropriate position. This slowness in spatial transfer of the left hand disappeared when he had to point to a part of his own body such as the nose, which was done quite smoothly.

Tests of verbal identification of common utensils by touch were performed 4 times and for each session none out of 5 items, 1 out of 7, 2 out of 3 and 2 out of 10 were correct. Again the left hand would not manipulate an item actively and would often remain just holding it. There was a tendency for the first or second item to be recognized correctly. Errors included perseverations of the previous answer and some inappropriate confabulations. Unlike form boards a multiple choice task, in which the patient had to recover a stimulus item from several objects in a bag, did not improve the results. Also he could not demonstrate the usage of the item. Overall this difficulty of object identification does not belong to tactile anomia (Geschwind, 1962) but to a category of astereognosis.

\section{Transfer of Somatokinesthetic Information to the Opposite Hand}

Cross-pointing of a touched locus by the opposite hand was incorrect bilaterally. Coarser localization such as identification of a passively flexed finger by flexing the corresponding finger of the opposite hand was also difficult. Replication of a passively imposed finger pattern by the other hand was impossible bilaterally.

\section{Performance in Other Modalities}

His audiogram was within normal limits bilaterally ranging from $16 \mathrm{db}$ to $-10 \mathrm{db}$. Bilateral finger snapping presented simultaneously was perceived correctly without extinction. Dichotic presentation of 2-digit series, however, demonstrated clear extinction of the left ear stimuli. In 2 test series the left-ear digits were correctly reported 2 out of 20 pairs and 0 of 19 pairs respectively, while the right-ear stimuli were perceived correct 17 out of 20 and 19 of 19 respectively. These digits which were extinguished were perceived $100 \%$ correct in the left ear if presented monaurally.

His visual field was normal. Simultaneous bilateral finger movement was perceived correctly. With $100 \mathrm{msec}$ tachistoscopic presentation of one or two Kana letters into either hemi-field those stimuli presented into the left visual field were read correctly 4 out of 13 and those presented into the right visual field were read correctly 12 of 14 . With simultaneous bilateral presentation, 0 out of 4 in the left and 4 out of 4 in the right visual field were read correctly. 


\section{Radiological Identification of Lesions}

An MRI scan was taken on the second day of admission, about 20 months after the accident. Lesion identification was done based on an Inversion Recovery image by comparison with a picture of an autopsied brain which was reduced to the same size with the MRI image. The frontal pole, the tip of the genu of the corpus callosum and the pons were used as a references point for comparison.

There was prominent ventricular enlargement in the lateral as well as the third ventricles. Low signal areas were seen scattered in the territory of the right anterior cerebral artery territory. Roughly area 8 of the medial superior frontal gyrus, the white matter of area 6 , the central portion of the cingulate gyrus and the overlying structure (area 23, 24, 31, and lower parts of area $4,3,1,2,5)$ showed change. The most important lesion was seen in the mid-portion of the corpus callosum occupying roughly one-third of the trunk of the corpus. The anterior portion of the corpus callosum including the genu and the posterior portion including the splenium seemed to have been spared. Because of hydrocephalus the corpus callosum got thinned in its total extension. No change was seen in the left hemisphere except for a small questionable low signal area in area 9 of the medial superior frontal gyrus.

A metrizamide infusion study was performed suspecting normal pressure hydrocephalus. Metrizamide was seen refluxing massively into the lateral ventrical in $3 \mathrm{~h}$ and remained trapped after $48 \mathrm{~h}$. Because of the finding

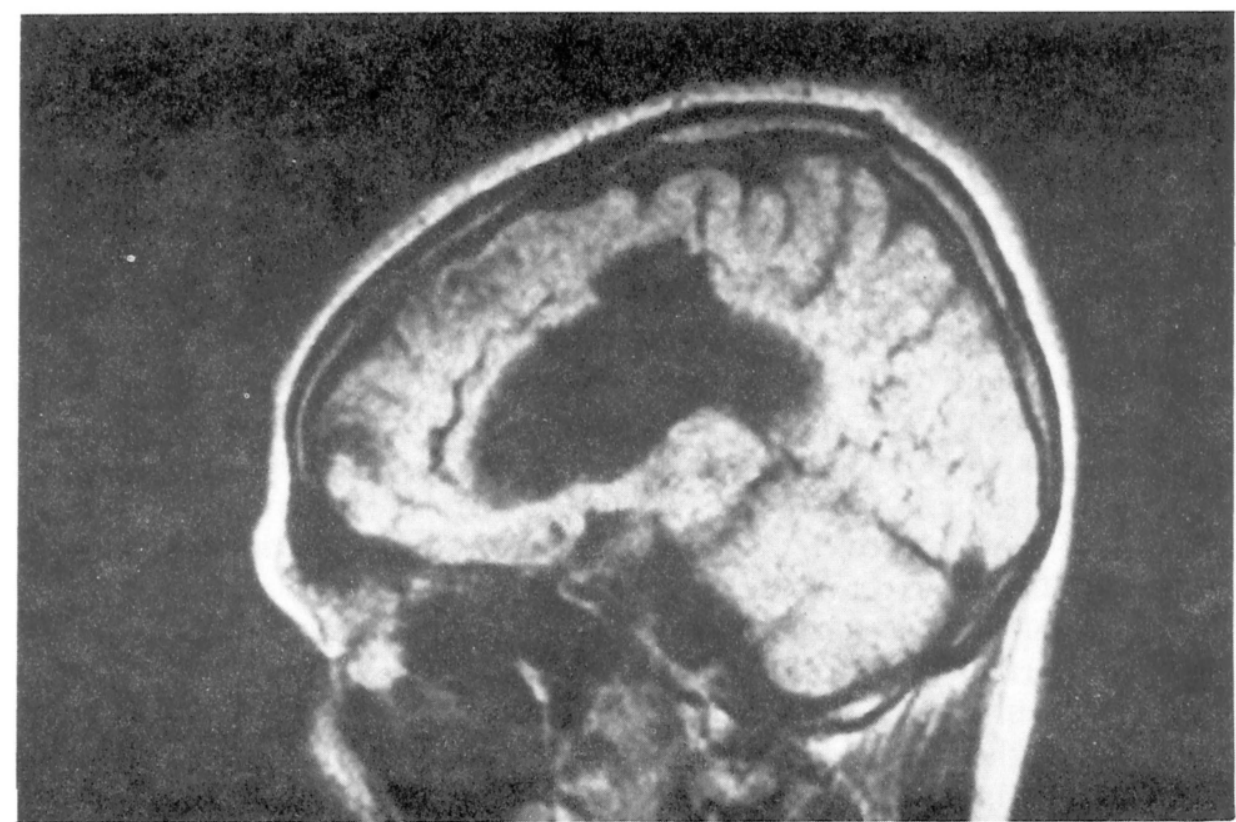

FIG. 1. MRI image of sagital section $10 \mathrm{~mm}$ right from the midline (15 Oct., 1986). Range of callosal lesion is well delineated. 


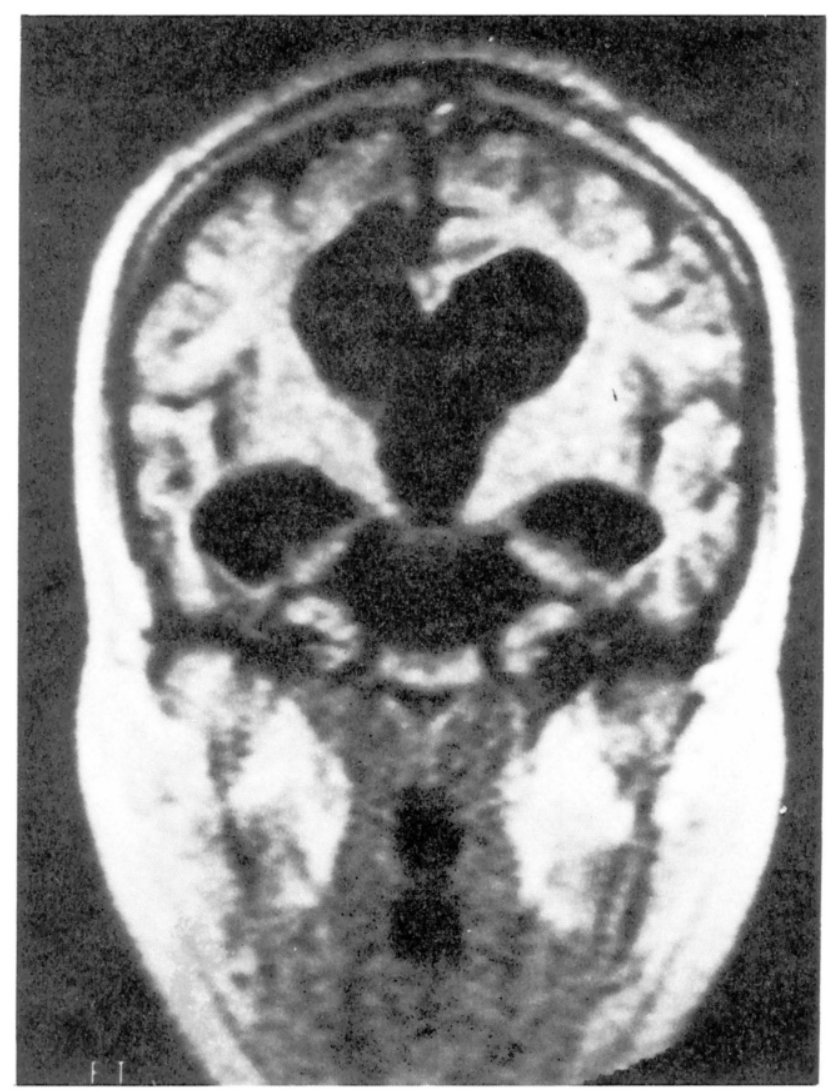

FIG. 2. Same MRI image of coronal section at a plane where callosal lesion is present.

a ventriculo-peritoneal shunt was replaced at the neurosurgical service. Despite this the patient remained unchanged and was discharged home on 15 November 1986, after one month's hospital stay.

\section{Summary of the Case}

This case showed left hand apraxia, left-hand motor initiation difficulty, left-hand clumsiness in stereognostic testing, left-hand agraphia, difficulty of tactile discrimination in the left hand, left-sided astereognosia, difficulty of intermanual transfer of tacto-kinesthetic information, left-ear verbal extinction and left-visual field letter alexia. Also the patient showed memory disturbance, low IQ emotional and personality change. His neuropsychological status is summarized in Table 1.

\section{Discussion}

Unlike a single stroke trauma may cause diffuse damage often in unexpected places making it difficult to locate lesions clinically by CT imaging. In the 


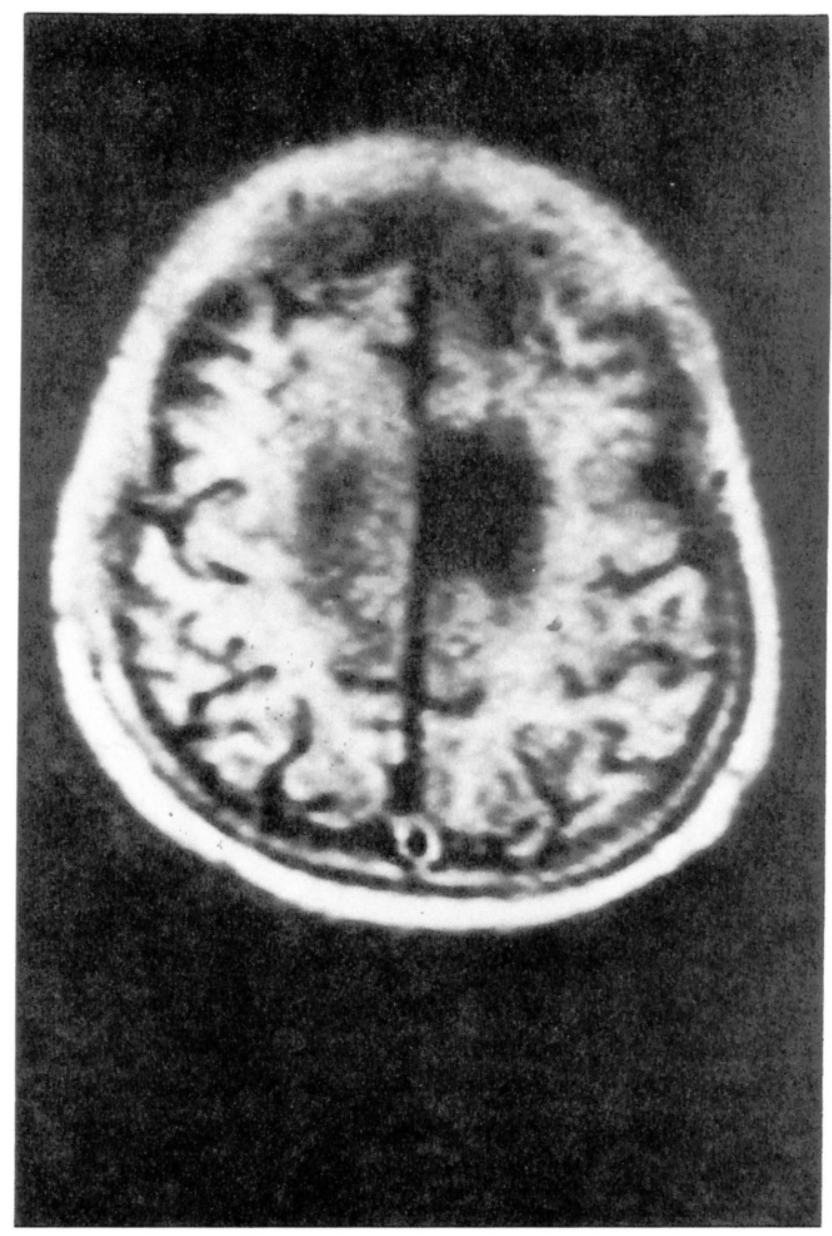

FIG. 3. Same MRI image of horizontal section at a level of the roof of the lateral ventricle.

present case the patient had prominent hydrocephalus necessitating replacement of A-P shunt. His dementia, personality change and gait disturbance could be explained by normal pressure hydrocephalus and some bilateral frontal lobe damage. However, despite these background changes the presence of numerous signs of strong right-left dissociation in motor, linguistic, tacto-kinesthetic, auditory and visual modalities could only be attributed to focal damage of the corpus callosum.

Motor difficulty of the present case was characterized by three types of functional dissociation. First, all the difficulties encountered in the left hand were performed smoothly by the right hand. Secondly, motor difficulty of the left hand elicitable by verbal and visual command disappeared when the information for movement was delivered tacto-kinesthetically to the same hand. Thirdly, the difficulties demonstrated in a testing situation could not be found in spontaneously behaving conditions.

To our knowledge three theories have influenced present thinking with 
TABLE 1. Summary of asymmetric symptoms between right and left hand of case T.S.

\begin{tabular}{|c|c|c|}
\hline & Left Hand & Right Hand \\
\hline \multicolumn{3}{|c|}{ Left Hand } \\
\hline initiation of action & - & + \\
\hline conventional sign gesture & - & + \\
\hline pantomime & - & + \\
\hline object manipulation & - & + \\
\hline elementary motor imitation & - & + \\
\hline sequential motor imitation & - & + \\
\hline writing & - & + \\
\hline bilateral coordination & + & + \\
\hline \multicolumn{3}{|l|}{ Sensory } \\
\hline topognosis & - & + \\
\hline two point localization & - & + \\
\hline graphesthesia & - & + \\
\hline stereognosis & - & + \\
\hline \multicolumn{3}{|l|}{ Sensori-Motor } \\
\hline cross-localization & - & - \\
\hline cross-replication of finger pattern & - & - \\
\hline ipsilateral replication & + & + \\
\hline $\begin{array}{l}\text { Visual } \\
\quad \text { tachistoscopic reading }\end{array}$ & $\begin{array}{c}\text { Left Field } \\
-\end{array}$ & $\begin{array}{c}\text { Right Field } \\
+\end{array}$ \\
\hline $\begin{array}{l}\text { Auditory } \\
\text { dichotic digit listening }\end{array}$ & $\begin{array}{c}\text { Left Ear } \\
-\end{array}$ & $\begin{array}{c}\text { Right Ear } \\
+\end{array}$ \\
\hline
\end{tabular}

Note (-) represents not normal performance and $(+)$ represents completely normal performance. Cross-localization was included to sensory-motor category because motor component (pointing) is involved.

regard to callosal apraxia. It has been proposed that left apraxia is a result of the failure of arrival of the verbal information at the right hemisphere (Geschwind, 1962, 1965, 1985). The second theory is similar but different in some critical details and explains the cause as impaired association of the verbal and motor information within the right hemisphere (Zaidel, 1977; Wilson, 1977). The third one argues that the left hemisphere contains visuokinesthetic motor engrams for learned movements and lack of these engrams in the right hemisphere causes left-side apraxia (Liepmann, 1908, 1920; Watson, 1983).

Obviously the first two theories can explain only such apraxia as becomes apparent in response to linguistic command. But this type of apraxia belongs to an exception rather than a rule, at least in naturally occurring lesions. In the majority of cases including the present one apraxia extends beyond verbal modality and affects visual as well as object handling (Liepmann, 1907; Iwata, 1980; Watson, 1983; Goldenberg, 1985; Graff-Radford, 1987). Thus both theories could explain the first and third dissociation quite well but are unsatisfactory for explaining the second dissociation. 
The third theory on the other hand could explain why verbal and visual stimuli fail to elicit normal left-hand movement. But it also has a difficulty. Assumption of the presence of motor engrams tacitly presupposes conceptual distinction between "learned" and "not-learned" movements. Analysis of our patient's difficulty does not allow this distinction however. Kinds of motor activities which were occasionally difficult to execute in the present case, such as raising the left arm, flexing a finger on imitation, or simple transfer of the left hand to an intended direction are difficult to categorize into learned movements. On the other hand, normal left-hand behaviour under natural conditions seems to imply intactness of learned motor movements. Motor perseverations often observed also implies intact motor learning system. Thus motor engram theory cannot explain the third dissociation.

These three dissociations can be easily explained if we assign to the left hemisphere a dominant role in motor activities which are realized only when conscious intention is involved. A typical instance when this type of action becomes necessary is when a subject has to regulate an action consciously into a particular space-time pattern according to a specific verbal or visual instruction. In this particular situation, which demands conscious monitoring of an action by a subject, relevant nervous activities would originate in the left hemisphere and be transferred to the right hemisphere via the corpus callosum. In situations where conscious intervention for motor realization is less required, such as in freely behaving conditions, motor control for the left hand does not necessarily have to originate in the left hemisphere. It could originate simultaneously in both hemispheres. It is very informative in this sense to recall that the present patient often stated that he had no idea what kind of pattern his left hand was taking at the very time when the left hand was reproducing a correct pattern in response to homolateral tactokinesthetic information. This underlines unconscious but well structured right hemisphere motor capacity.

It has to be remembered at this point that the importance of motor capacity dissociation between commanding and autonomic situation was recognized by Jackson as early as 1878 concerning tongue-protrusion (Jackson, 1878). In his early formulation of apraxia Liepmann was also eager to emphasize its purposive aspect (Liepmann, 1905). As far as left-side apraxia is concerned, this important aspect has receded from the foreground as analysis of symptoms acquired sophistication. Yet this factor remains the most crucial clue for understanding apraxia.

The present case also showed difficulty in manipulating objects. This difficulty has often been seen associated with naturally occurring left callosal apraxia (Liepmann, 1907; Goldstein, 1908; Watson, 1983; Iwata, 1980; Nakatani, 1984; Satomi, 1985; Graff-Radford, 1987). Part of this difficulty can also be explained by lack of intentional motor component. However, since the present patient also had difficulty in fine discriminatory tactile capacity such as point localization, two point discrimination, agraphesthesia and stereognosis, the principal reason in defective object handling must be attributed to clumsiness often seen associated with astereognosis (Campora, 
1925). Elsewhere we have proposed to call this type of clumsiness palpatory apraxia (Yamadori, 1982) which belongs to the limb-kinetic type of apraxia totally different from disconnetion (callosal) apraxia. Whether the tactile difficulty of the present patient was also part of a disconnetion sign or a manifestation of a possible right-hemispheric parietal damage cannot be determined by the present data.

The main lesion of the corpus callosum in the present case was seen in the posterior truncus of the corpus callosum. This location is in accordance with reported cases of callosal apraxia (Iwata, 1980; Volpe, 1982; Watson, 1985; Kawamura, 1986). This lesion site had been suggested by the founder of the callosal theory himself (Liepmann, 1907).

In addition our patient's lesions included medial fronto-parietal area of the right hemisphere along with questionable left medial frontal region. A possibility of contributions of these extra-callosal lesions to the genesis of left apraxia has been suggested (Gazzaniga, 1967). It is true that most of the well circumscribed naturally occurring lesions reported are due to infarctions of the left anterior cerebral artery (Liepmann and Maas, 1907; Geschwind, 1962; Ohigashi, 1983; Satomi, 1985) but it is also true that there are rare cases due to right anterior cerebral artery infarction (Goldstein, 1908; Iwata, 1980). The present case although not an infarction also had the right extra-callosal damage. The fact that left apraxia is produced regardless of the side of extra-callosal lesion strongly favours a notion that the essential lesion responsible for left apraxia is in their common lesion, i.e. the corpus callosum.

Against these lines of reasoning a contribution of the medial frontal damage to the genesis of apraxia has recently been suggested (Goldenberg, 1985 ) but the fact that there are cases of left apraxia without any extracallosal medial frontal damage (Watson, 1985; Graff-Radford, 1987) seems to speak against this assumption. It also has to be remembered that even in surgical cases left unilateral apraxia is consistently seen at least in its acute stage (Bogen, 1979; Wilson, 1977). Thus it is more probable to assume that the individual difference of the severity of left apraxia in chronic callosal patients is due primarily to differences of right-hemispheric reorganization in the face of information deprivation from the left hemisphere.

\section{References}

Alajouanine, T. (1960). Baillarger and Jackson; The principle of Baillarger Jackson in aphasia. Journal of Neurology, Neurosurgery and Psychiatry, 23, 191-193.

Bender, M. B., Stay, C. and Cohen, J. (1982). Agraphesthesia. A disorder of directional cutaneous kinesthesia or a disorientation in cutaneous space. Journal of Neurological Sciences, 53, 531-555.

Bogen, J. E. (1979). The callosal syndrome. In "Clinical Neuropsychology". (Eds. K. M. Heilman and E. Valenstein) pp. 308--359. Oxford University Press, New York.

Campora, G. (1925). Astereognosis: its causes and mechanism. Brain, 65, 65-71.

Gazzaniga, M. S., Bogen, J. E. and Sperry, R. W. (1967). Dyspraxia following division of the cerebral commissures. Archives of Neurology, 16, 606-612.

Geschwind, N. (1965). Disconnexion syndromes in animals and man. Brain, 88, 237-294, $585-644$. 
Geschwind, N., Damasio, A. R. (1985). Apraxia. In "Handbook of Clinical Neurology", Vol. 1 (45), Clinical Neuropsychology. (Ed. J. A. M. Frederiks), pp. 423-432. Elsevier Science Publishers, Amsterdam.

Geschwind, N. and Kaplan, E. (1962). A human cerebral deconnection syndrome. Neurology, $12,675-685$.

Goldenberg, G., Wimmer, A., Holzner, F. and Wessdy, P. (1985). Apraxia of the left limbs in a case of callosal disconnection: the contribution of medial frontal damage. Cortex, 21, $135-148$.

Goldstein, K. (1908). Zur Lehre von der motorischen Apraxie. Journal für Psychologie und Neurologie, 11, 169-187; 270-283.

Graff-Radford, N. R., Welsh, K. and Godersky, J. (1987). Callosal apraxia. Neurology, 37, $100-105$.

Iwata, M., Sugishita, M., Yoshida, S. and Toyokura, Y. (1980). Left unilateral ideo-motor apraxia due to the lesion in the posterior half of the corpus callosum. Clinical Neurology, 20, 721-727 (in Japanese).

Jackson, H. (1878). Remarks on non-protrusion of the tongue in some cases of aphasia. Lancet, 1, 716.

Kawamura, M. and Hirayama, K. (1986). Interhemispheric disconnexion syndrome due to callosal lesions and its diagnosis by magnetic resonance imaging. Advances in Neurological Sciences, 30, 461-473 (in Japanese).

Liepmann, H. (1905). "Über Störungen des Handelns bei Gehirnkranken". S. Karger, Berlin.

Liepmann, H. (1908). Über die Funktion des Balkens beim Handeln und die Beziehungen von Aphasie und Apraxie zum Intelligenz. In "Drei Aufsätze aus dem Apraxiegebiet", pp. 51-78. Karger, Berlin.

Liepmann, H. (1920). Apraxie. Brugsche Ergebnisse der gesamten Medizin, 1, 516-543.

Liepmann, H. and Maas, O. (1907). Fall von linksseitiger Agraphie und Apraxie bei rechtsseitiger Lähmung. Fournal für Psychologie und Neurologie, 10, 214-227.

Luria, A. R. (1966). "Higher Cortical Functions in Man". Basic Books, New York.

Nakatani, T., Watanabe, J., Tashiro, T., Takeishi, S., Hosoda, K., Uemura, K. (1984). A case of posttraumatic interhemispheric disconnection syndrome. Brain Nerve, 36, 65-71 (in Japanese).

Ohigashi, Y., Hamanaka, T., Asano, K. and Morimune, S. (1983). Left unilateral agraphia. Its characteristics and dynamics. Brain Nerve, 35, 1065-1072 (in Japanese).

Rubens, A. B., Geschwind, N., Mahowald, M. W. and Mastir, A. (1977). Posttraumatic cerebral hemispheric disconnection syndrome. Archives of Neurology, 34, 750-755.

Satomi, K. and Goto, K. (1985). A case of callosal apraxia after left cerebral artery occlusion. Clinical Neurology, 25, 443-447 (in Japanese).

Volpe, B. T., Sidtis, J.J., Holtzman, J. D., Wilson, D. H. and Gazzaniga, M. S. (1982). Cortical mechanisms involved in praxis: Observations following partial and complete section of the corpus callosum in man. Neurology, 32, 645-650.

Watson, R. T. and Heilman, K. M. (1983). Callosal apraxia. Brain, 106, 391-403.

Watson, R. T., Heilman, K. M. and Bowers, D. (1985). Magnetic resonance imaging (MRI NMR) scan in a case of callosal apraxia and pseudoneglect. Brain, 108, 537--554.

Wilson, D. H., Reeves, A., Gazzaniga, M. and Culver, C. (1977). Cerebral commissurotomy for control of intractable seizures. Neurology, 27, 708-715.

Yamadori, A. (1982). Palpatory apraxia. European Neurology, 21, 277-283.

Zaidel, D. and Sperry, R. W. (1977). Some long-term motor effects of cerebral commissurotomy in man. Neuropsychologia, 15, 193-204. 


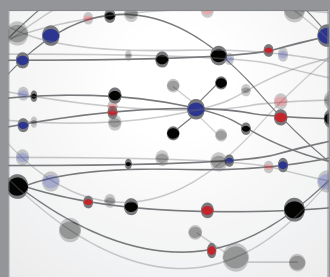

The Scientific World Journal
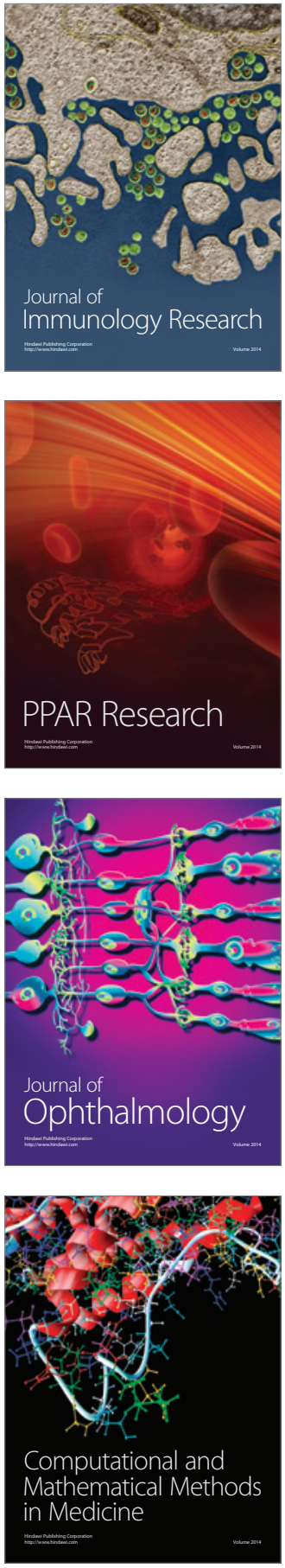

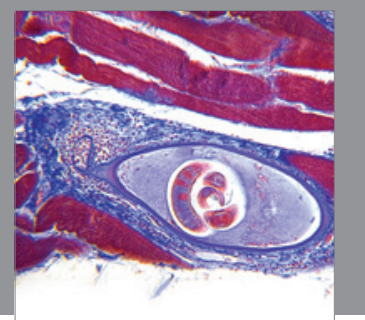

Gastroenterology

Research and Practice
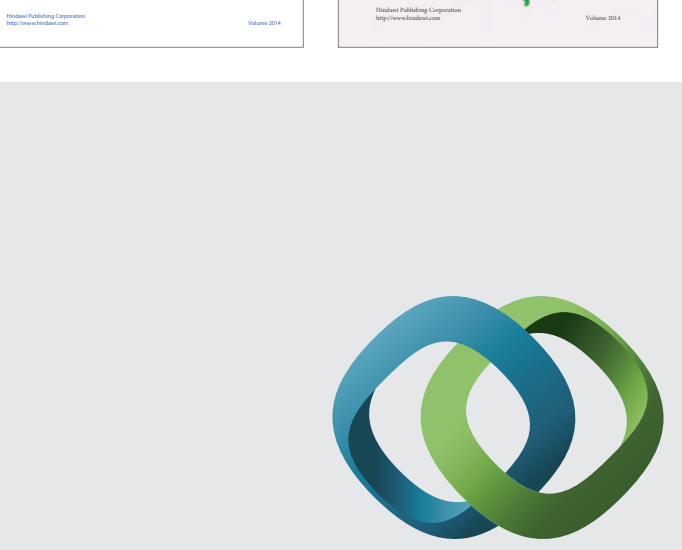

\section{Hindawi}

Submit your manuscripts at

http://www.hindawi.com
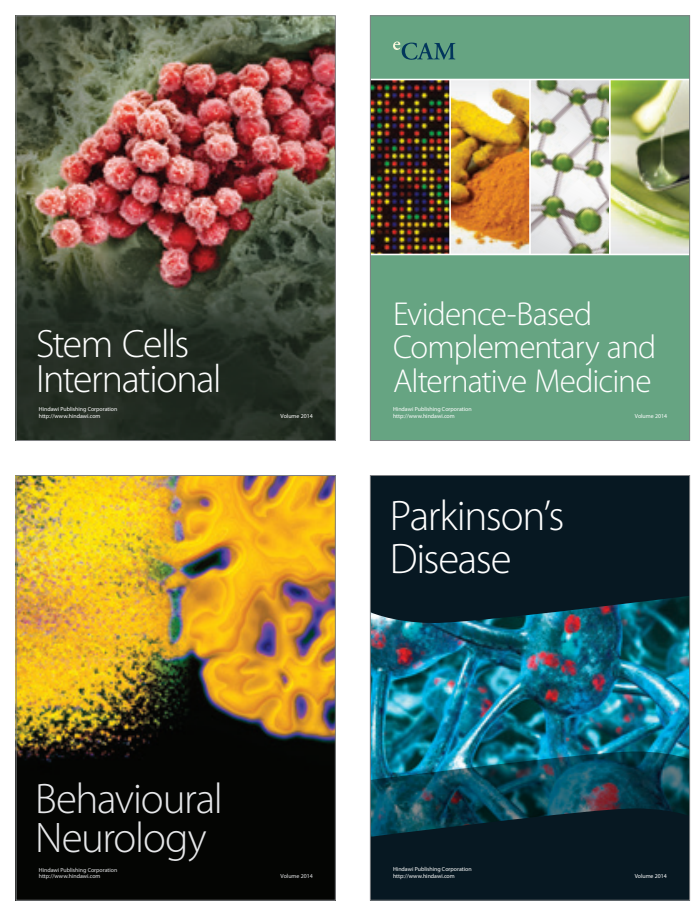

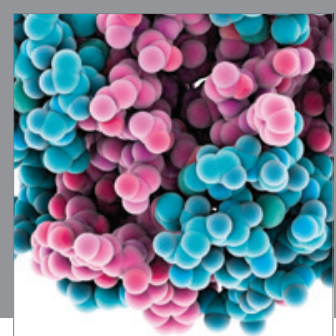

Journal of
Diabetes Research

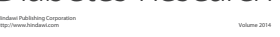

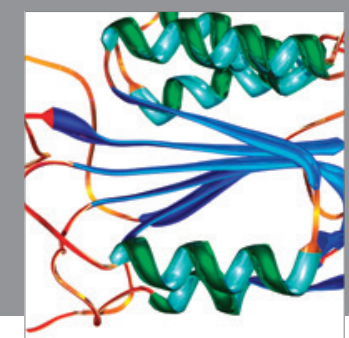

Disease Markers
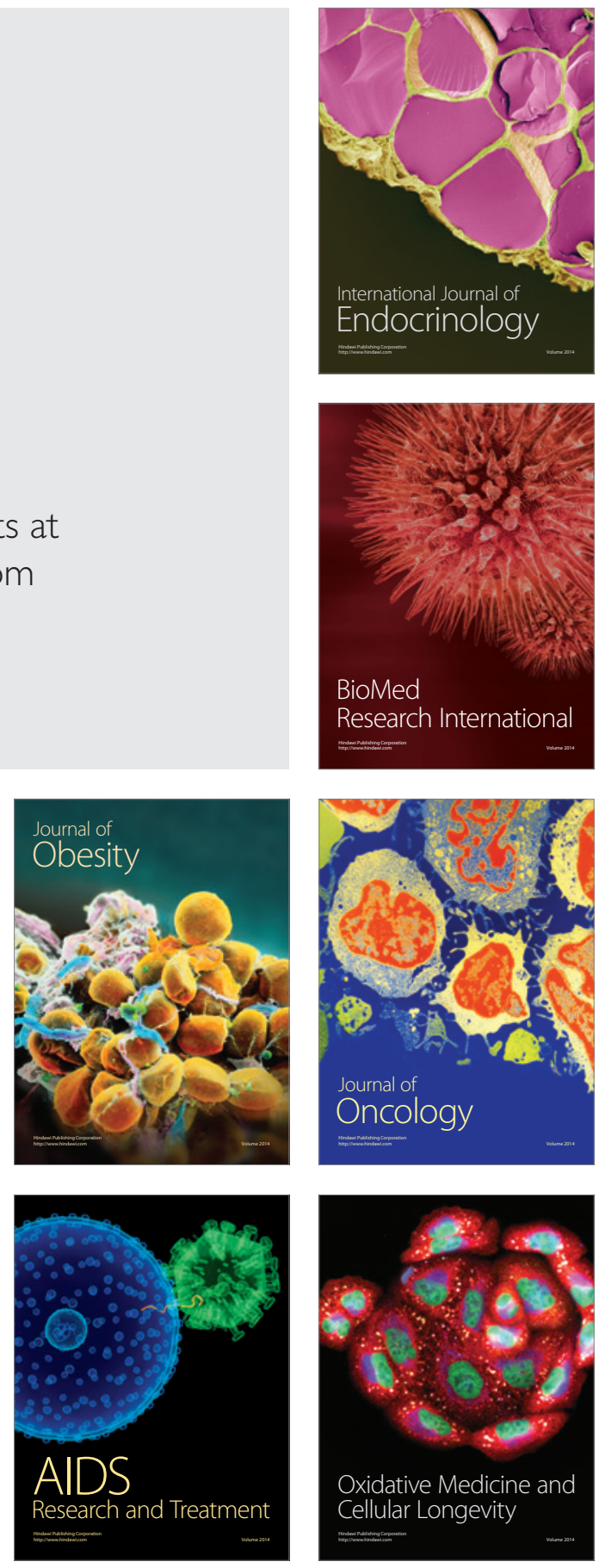